REMATEE DE MALES

Campinas-SP, v.41, n.1, pp. 45-59, jan./jun. 2021

\title{
Moishe Postone e o ensaio como Forma ${ }^{1}$
}

\author{
Moishe Postone And the Essay as Form
}

\author{
Robert Hullot-Kentor ${ }^{2}$
}

Em memória afetuosa

Resumo: O presente ensaio esboça brevemente a relação entre Tempo, trabalho $e$ dominação social, a principal obra de Moishe Postone, e uma linha de desenvolvimento filosófico da qual, por ser uma teoria crítica, ela seria inerentemente uma aliada: o trabalho de Theodor Adorno, tal como é paradigmaticamente realizado no "ensaio como forma", expressão que aqui serve de apóstrofe ao modo de Adorno proceder como um todo, e não como uma referência estrita a seu conhecido ensaio. Ainda que o estudo de Postone almeje e seja uma reflexão dialética, ele busca a univocidade. E, ao se alinhavar dessa forma, repudiando toda divagação, como uma forma de análise categorial, ele se diferencia decisivamente do ensaio como forma por rejeitar a crítica imanente. Porém, embora reconheçamos o alcance da exclusividade mútua entre o ensaio como forma enquanto crítica imanente e uma análise categorial sistemática da totalidade - como a de Postone -, essa antipatia não precisa ser entendida como sendo obrigatoriamente improdutiva. Caso perseguida, ela pode até vir a ter implicações para a liberação de tudo aquilo que está contido como um híbrido na expressão "marxismo tradicional", desprendendo das aspas a experiência histórica e mesmo as palavras nela alojadas, sem colocar em risco a reflexão sistemática do Marx maduro que Moishe acertadamente desejava discernir e elucidar.

Palavras-chave: Moishe Postone; Theodor Adorno; ensaio como forma.

\footnotetext{
${ }^{1}$ N.T.: este texto foi publicado originalmente em inglês como "Moishe Postone and the Essay as Form», na revista Critical Historical Studies (v. 7, n. 1, Spring 2020, pp. 9-18).

${ }^{2}$ Robert Hullot-Kentor é um dos principais estudiosos da obra de Theodor Adorno nos Estados Unidos. É autor do livro de ensaios Things Beyond Resemblance (Columbia U. P., 2006), além de ter traduzido para o inglês Kierkegaard: a construção do estético, Filosofia da nova música e a Teoria estética, entre outros ensaios de Adorno. Foi professor de filosofia, literatura e artes nas universidades de Harvard, Boston e Stanford, bem como na School of Visual Arts, em Nova York.
} 


\begin{abstract}
The essay at hand briefly sketches out the relation of Moishe's major work Time, Labor and Social Domination to a philosophical development with which, as critical theory, it is inherently allied: the work of Theodor Adorno, as it is paradigmatically given in the "essay as form," here a phrase apostrophizing Adorno's way of proceeding altogether, not strictly citing the much studied eponymous essay. Although Moishe's study means to be and is dialectical reflection, it nevertheless seeks univocality. And in pursuing this tack, in holding the compass straight and repudiating divagation, as a form of categorial analysis, it differentiates itself decisively from the essay as form by rejecting immanent criticism. Yet, even as we recognize the extent of the mutual exclusivity of the essay as form as immanent criticism and a systematic categorial analysis of totality, this antipathy is not to be understood as obligatorily unproductive. Pursued, it might well have implications for the release of all that is bound up as a hybrid in the phrase "traditional Marxism," extricating the historical experience and even the words Marxism," extricating the historical experience and even the words lodged within it from scare quotes, without endangering the systematic insight of the mature Marx that Moishe rightly wanted to discern and elucidate.
\end{abstract}

Keywords: Moishe Postone; Theodor Adorno; Essay as form.

Quando muitos de nós presentes aqui hoje estivemos, na primavera passada, falando sobre Moishe - Marty Jay e Cathy Gallagher estavam de visita em Nova York e falávamos justamente sobre ele quando perguntei a Cathy o que fazia com que Moishe fosse tão amável. ${ }^{3}$ Ela já havia pensado sobre isso, tenho certeza, já que, um momento depois, para entender o que ela havia dito, tive de voltar ao que eu acabara de ouvir, "Bom, ele era alguém tão presente”. Cathy fala muito rápido. Mas é verdade, decidi, ao alcançá-la após mais um momento. Moishe estava bem ali. Pode-se pensar na organização mental, urgente e analítica; em uma polidez inatamente cuidadosa, que nele de algum modo se juntava a uma recusa completa a deixar passar quaisquer mal-entendidos; e tem-se em mente em especial a clareza focada de sua voz, como se como se ele estivesse mais para filho de cantor do que de rabino. A primeira vez que ouvi uma fala de Moishe, quando eu já não era de modo algum um jovem, foi também a primeira vez que entendi, da primeira à última sílaba, uma palestra de uma hora, ainda podendo concluir que tê-la ouvido talvez me tenha feito algum bem. Quando depois falei sobre a palestra com Moishe, de maneira elogiosa e para me apresentar, ele de algum jeito me deu a entender que o feito tinha sido todo meu. Mas o que eu mais sentia na presença de Moishe, o que todos nós tínhamos de reconhecer nele, conscientemente ou não, era

\footnotetext{
${ }^{3}$ Moishe Postone, 17 abr. 1942 - 19 mar. de 2018. Uma versão consideravelmente reduzida deste texto foi lida na conferência "Capitalism and Social Theory: A Conference in Memory of Moishe Postone”, organizada por William Sewell e Jonathan Levy no Chicago Center for Contemporary Theory, University of Chicago, 12-13 abr. 2019.
} 
alguma parte da humanidade fugitiva que, muito antes de Moishe chegar aqui nos Estados Unidos vindo do Canadá, já havia coberto muito mais quilômetros do que isso, e não só nessa direção, e não só como alguém em fuga. Ouvia-se a dicção exata de Moishe, de perto, perguntando-se sobre que língua de fato estava sendo falada. Eu não teria dito isso a ele - e hesito em dizê-lo agora -, mas eu o considerava um parente muito distante, ligado por um número de laços consideravelmente maior do que seis milhões. O compromisso de Moishe Postone era com um monoteísmo do texto, como se esse mundo não pudesse de jeito nenhum existir sem um livro por meio do qual pudesse ser conhecido, frase a frase, como se, caso pudéssemos só ler o livro direito e tê-lo na ponta da língua, conseguíssemos botar em ordem as muitas tradições falsas - a começar por aquilo que ele caracterizava como o "marxismo tradicional". O esforço de Moishe por resgatar do marxismo tradicional o Marx "maduro" era feito com nada menos do que a intenção de cancelar de vez a demanda da História por suas hecatombes. Aquilo que tem sido, ele tomou como responsabilidade sua. Na penúltima nota que tenho de Moishe, escrita de Viena em 6 de novembro de 2017, ele não mencionou o estado de sua doença, mas deixou mais do que claro que não se sentia bem. "Nunca me senti tão desolado. Os EUA são um show de horrores e, como você sabe, as coisas parecem ir mal na Áustria. Penso que é em parte um fracasso da Esquerda" (POSTONE, 2017, 16 nov.).

Escrevi a Moishe naquela noite e, na manhã seguinte, lá estava ele:

Quando você diz que nós [isto é, a Esquerda] éramos um clube de boliche [que é o que eu havia escrito em minha nota a ele] - é isso o que eu quero dizer com um fracasso da Esquerda - imaginar ideias que teriam apelo para muitas pessoas de fora dos nossos círculos (POSTONE, 2017, 17 nov.). ${ }^{4}$

No momento daquela correspondência, como sabemos todos, muitas pessoas, parte das quais aqui presente, estavam de fato construindo ideias para a Esquerda, especialmente em nível de plataformas políticas, no sentido da disputa vigorosamente comprometida em torno de a quem cabe o quê. Um movimento vem tomando forma. Mas, deixando de lado as inevitáveis ironias de Minerva e deixando também de lado minha imagem espalhafatosa do clube de boliche, eu gostaria hoje de tomar o comentário de Moishe como ponto de partida. Estou certo de que muitas outras passagens de sua obra seriam escolhas melhores. Mas fico com esse

${ }^{4}$ Grifo nosso nesta e nas citações subsequentes. 
comentário, escrito de maneira tanto informal quanto a sério, porque estamos aqui nos lembrando de Moishe, e essa foi a última nota que recebi dele. Seu comentário de que a esquerda não tinha até então sido capaz de "imaginar ideias que tivessem apelo" para todos aqueles "de fora de nossos círculos" permanece agudamente relevante para uma esquerda que precisa agora entender e dar forma ao que entende por socialismo. Pois a necessidade de uma teoria enquanto teoria, no sentido do pensamento que agarra o novo - como aquilo que é visto pela primeira vez - de modo algum diminuiu; nem a atividade concentrada de organização é em si mesma prova de que o claustro das percepções mais importantes da Esquerda foi violado.

Nesse sentido, o comentário de Moishe tem motivos para ser preocupante. Pois eleapresenta a experiência do pensamento, nada inédita, conforme encontra um limite, uma barreira ou um bloqueio, uma espécie de cerca que se materializa sem explicação, e o pensamento é obrigado a reconhecer que seu próprio objeto foi deslocado para o lado de lá dessa cerca e lhe escapou, de algum modo recuando continuamente para além do alcance. Sabemos todos que essa charada não existe só para a Esquerda contemporânea, mas sim que é tão velha quanto a origem do marxismo, que a cada ponto de sua história buscou fornecer manifestos e versões popularizadas, livros vermelhos e introduções à economia, e paisagens de bonecos de palito desenhados em lousas para demonstrar a suposta simplicidade de sua lógica para aqueles a quem ela mais diz respeito, aqueles que seriam o objeto efetivo de suas reflexões. Essa charada, que nunca sai de vez das nossas cabeças, é digna de ser considerada em voz alta por um momento. Pois se é verdade, como Moishe repetidamente busca demonstrar em sua elucidação do Marx maduro, que esse jeito de pensar nos leva até o ponto exato em que podemos testemunhar aquilo que é conforme se escancara enormemente sua distância daquilo que poderia ser e (como Moishe não menos insiste) o faz por meio de conceitos que seriam em si mesmos tidos como os conceitos de uma práxis que saltaria através desse vão, então por que - nas próprias palavras da nota de Moishe - a imaginação e o apelo precisam de alguma forma ser acrescentados ao raciocínio quase como que de última hora, como se, de outro modo, ele não pudesse falar de maneira convincente e sedutora para aqueles a quem é dirigido?5 $\mathrm{O}$ que significaria, mesmo se só até certo ponto, buscar

${ }^{5}$ Cf. Postone e Brennan, 2009, p. 325. 
tornar claro esse bloqueio ao invés de, na fronteira final das perquirições das ciências sociais, acabar tentando botá-lo em panos quentes, talvez acrescentando um toque de imagística, bom humor e uma linha narrativa que leve adiante os pontos de discussão?

Para refletir sobre essa questão, eu gostaria de esboçar brevemente a relação entre a principal obra de Moishe e uma linha de desenvolvimento filosófico da qual, por ser uma teoria crítica, ela seria inerentemente uma aliada. A teoria crítica, em sentido literal, compreende uma história substancial do pensamento e tem como mínimo denominador comum o exame de conceitos na medida em que estes possam ir longe demais e exceder a si mesmos, e que em uma de suas linhas de desenvolvimento é essencialmente voltada para entender "o bloqueio" (ADORNO, 1969-1970, p. 153; 1981, pp. 384-390). ${ }^{6}$ Trata-se do trabalho de Theodor Adorno tal como é paradigmaticamente realizado no "ensaio como forma", expressão que serve aqui de apóstrofe ao modo de Adorno proceder como um todo, e não uma referência estrita ao ensaio epônimo e muito estudado, o qual, antes da escrita da Dialética negativa, Adorno considerava como a formulação privilegiada de sua filosofia, ao lado da introdução à Metacrítica da epistemologia (ADORNO, 1984a, pp. 151-171; 2013). O ensaio como forma é uma obra em fragmentos. Cada elemento, incluindo aí elementos de teoria, deve ficar à mesma distância do ponto médio, parataticamente. Como uma crítica do bloqueio, a forma do ensaio, enquanto forma, se engaja com cada aspecto da obrigação que Moishe nos confia na última nota que tenho dele, aquela de imaginar ideias que teriam apelo para muitas pessoas de fora dos nossos círculos, uma declaração que de forma consideravelmente condensada evoca o tegumento de ideia, imaginação e desejo no qual muito do pensamento ocidental está escrito. Na obra de Adorno, essa constelação de pensamento se espalha a partir do modo como desenvolve o conceito e a mímesis. A intenção do ensaio como forma é a de reconciliar razão e mímesis, discursividade e semelhança, sem diminuir a oposição de uma a outra. O desiderato dessa reconciliação paradoxalmente conflituosa é, como Adorno escreve, a dedução do conceito a partir de seu objeto, ao invés do objeto a partir de seu conceito. Isso, deduzir o objeto a partir de seu conceito, resultaria por assim dizer na montagem da cerca. Sua crítica - a crítica do bloqueio -, em contraste, seria constatada,

\footnotetext{
${ }^{6}$ N.T.: Na tradução brasileira: Adorno (2009, pp. 318-323). Por conta do sentido que a expressão assume ao longo do argumento de Hullot-Kentor, contudo, a solução aqui encontrada foi optar pelo termo "bloqueio" ao invés de "bloco".
} 
no âmbito da insuficiência reconhecida do conceito com relação a seu objeto, como sendo a experiência da primazia do objeto, percebida na transitoriedade do conceito. Seguindo a concepção de Adorno (1986a, p. 301) sobre a imaginação, essa seria uma instância da fantasia exata - aqui a experiência conceptualizada da possibilidade inerente a seu objeto como o "desejar direito", um ato de negação determinada. ${ }^{7}$

Tenho noção de que essas últimas frases tanto são chover no molhado quanto imitação de segunda; como uma apresentação dogmática e talvez evocativa do ensaio como forma - e nada disso pode ser compreendido vindo da frente de uma sala e sendo ouvido por alguém que não esteja familiarizado com isso -, ela está em oposição direta à forma de apresentação a ser elucidada, e é difícil proceder de outro modo, conforme o testemunho de boa parte da literatura sobre Adorno. Ainda que Adorno, cujo pensamento filosófico tem origem na epistemologia, tenha escrito largamente sobre sua própria abordagem, ele considerava declarações semimetodológicas como aquelas acima esboçadas como sendo enganadoras. Em oposição a isso - e com insistência crescente em sua obra tardia -, ele sustentava que a crítica da reificação só teria sentido como crítica da linguagem. A intenção do ensaio como forma não é nada menos do que tornar carne o verbo, ainda que não no sentido da creatio ex nihilo, mas como história natural. Se em seus extremos - como diz o muito conhecido filosofema de Adorno muito conhecido sobre a história natural - a história deve ser reconhecida como natureza e a natureza, como história, então essa tese encontra o teste crucial, senão seu experimentum crucis, na razão discursiva, no extremo da convenção. ${ }^{8}$ Onde aquilo que é irredutivelmente conceitual é, lá é que a história natural deve ser articulada, na afinidade mais próxima com a psicanálise e em distância absoluta com relação a ela. A transitoriedade interpretada do conceito, ao registrar negativamente o anseio por seu objeto, é o elemento da natureza a ser reconhecido pela razão discursiva. Não é preciso dizer que isso seria uma crítica imanente. Esses próprios conceitos são nada menos do que

\footnotetext{
7 Sobre "desejar direito" [right wishing], cf. "Richtig wünschen ist die schwerste Kunst von allen, und sie wird uns seit der Kindheit abgewöhnt” (ADORNO, 1986c, p. 516.), bem como "Wahr wäre der Gedanke, der Richtiges wünscht" (1986b, p. 399). [N.T.: Na tradução brasileira: "[...] verdadeiro seria o pensamento que deseja algo correto" (2009, p. 86). Contudo, como a conclusão do ensaio de Hullot-Kentor depende de certa ambiguidade imprevista na expressão "right wishing", a solução aqui encontrada foi adaptá-la como "desejar direito", ao invés do "deseja algo correto" que aparece na tradução brasileira.]

${ }^{8}$ Cf. Adorno, 1984b, pp. 111-124.
} 
palavras cujo ideal, no ensaio como forma, é o de falarem por si mesmas, ao invés de se apropriarem da posição de uma perspectiva de algo que lhes seja externo, ou comentar por meio de argumentos em raciocinação encenada, ou percorrer uma linha narrativa em torno do tema.

A obra de Moishe Postone, sendo teoria crítica, consiste tão completamente numa análise categorial quanto a de Adorno, mas o ensaio como forma não poderia ter a ver quase de nenhum modo com os muitos ensaios de Moishe, e certamente não com sua obra principal. Moishe tinha excelentes razões para tanto. Ele queria formular uma teoria que fosse tão internamente consistente quanto possível e - conforme sua repetida invocação - poderosa, adequada, e sofisticada. ${ }^{\text {Tempo, }}$ trabalho e dominação social são assim; e, ainda que considere remota a meta, busca nada menos do que entender o capitalismo completamente e sem deixar resto. A obra é regida pelo princípio do non confundar in aeternum: que eu não me perca do caminho. Se aquele a quem Moishe deve o nome foi uma figura com um senso considerável sobre a lei e um senso proporcionalmente pobre de direção, precisando de 40 anos no deserto para se orientar rumo à providência, o senso de urgência que Moishe tinha com relação à história do século XX não era de modo algum providencial. Qualquer que fosse seu monoteísmo do texto, ele não estava a serviço de errâncias velho-testamentais. Assim, a escrita de sua obra prima é toda ela a do raciocínio consecutivo, uma construção vigilante de períodos hipotáticos organizados de modo a excluir qualquer pensamento fragmentário. O estudo categorial que ele desenvolveu é apresentado sem ruminações sobre a filosofia da linguagem, sob o pressuposto, compartilhado com Hegel, de que a palavra é inteiramente transparente ao conceito. ${ }^{10}$ Sua elucidação do conceito de "fetiche", por exemplo, serve como baliza, sem se distrair com o tom irônico de Marx ou com o intenso aprofundamento do conceito ao longo do século XX, com a descoberta do primitivo em nós mesmos. Da mesma forma, ainda que condene o marxismo "tradicional", por ter substituído o entendimento correto do Marx maduro e em seu lugar afirmado o ponto de vista do trabalho, em outro lugar de seu texto ele define a ideia de tradição - como

\footnotetext{
${ }_{9}$ Ver, por exemplo, a última frase de Postone (1993, p. 399): "Marx’s critical theory [...] is [...] a powerful argument, regarding the nature of an adequate social theory”. [N.T.: Na edição brasileira: "A teoria crítica de Marx [...] é [...] um poderoso argumento sobre a natureza de uma teoria social adequada" (POSTONE, 2014, p. 463).]

${ }^{10}$ Cf. Lebrun (1972).
} 
quando discute a "sociedade tradicional" - como sendo aquela na qual o trabalho é "imanente à sociedade", em outras palavras, como o contrário exato de uma sociedade construída sobre o trabalho mercadorizado ou o pensamento que caracteriza o "marxismo tradicional" (POSTONE, 1993, p. 171). É só porque palavra e conceito são metodologicamente assumidos como descolados - até o ponto em que um estudo textual cerrado de Tempo, trabalho e dominação social demonstraria que o autor desconsidera os sinônimos como sendo distrações terminológicas - que é possível para Moishe prescindir da reflexão sobre a complexidade no conceito de tradição que seu uso do termo implicitamente envolve. Ouvida naquilo que tem a dizer, a palavra "tradição" em si mesma pede por mais do que qualquer uso técnico do conceito estaria pronto para admitir quando é empregado a serviço da clareza. As implicações no tratamento dessa única palavra têm largo alcance na obra de Moishe, já que ela desamarra abruptamente o esforço humano da pesquisa com que o estudo sem dúvida busca se engajar. Pois, mesmo quando vista sob a ótica do mais parcial dos panoramas, a "tradição" do "marxismo tradicional" tem sido uma disputa freneticamente sangrenta.

Assim, ainda que o estudo de Moishe almeje e seja uma reflexão dialética, não obstante ele busca a univocidade. E, ao se alinhavar desta forma, ao segurar firme a bússola e repudiar a divagação, como uma forma de análise categorial, ele se diferencia decisivamente do ensaio como forma por rejeitar a crítica imanente. Conforme Moishe explicou em diversas ocasiões, ele chegou a sua compreensão-chave do Marx tardio por meio dos Grundrisse, que conseguiram esclarecer para ele certos aspectos de Marx apenas e exatamente pelo fato de que os Grundrisse não são organizados como crítica imanente, à diferença d'O capital (POSTONE, 1993, p. 21). ${ }^{11}$ Moishe estava convencido, talvez acertadamente, de que foram as ambiguidades inerentes à crítica imanente, o fato de que a crítica imanente evita a perspectiva, que permitiram que o Marx tardio tenha sido paradoxalmente apropriado pela perspectiva do marxismo tradicional. É consistente, então, que Moishe se refira ao Marx maduro ao longo de seu estudo - em suas próprias palavras - como "a crítica do trabalho" e nunca como uma perspectiva alternativa à perspectiva do marxismo tradicional. Mas esses esforços metodológicos, buscando a garantia da clareza, produzem obscuridades próprias. Pois é de modo involuntário que surge

${ }^{11}$ Ver também Postone e Brennan (2009, p. 307). 
um híbrido no qual o marxismo tradicional, identificado como perspectiva, acaba ele mesmo fretado pela rejeição que Moishe faz da crítica imanente na forma expositiva de sua própria obra. E, de outro lado, seu estudo busca vir ao resgate de uma obra de crítica imanente - Das Kapital - ao explicar repetidamente a importância da crítica imanente e esmiuçando-a, por meio de uma abordagem em perspectiva vigorosamente argumentada, e que é declarada como a sua própria. ${ }^{12}$

Essa abordagem em perspectiva é levada a cabo de modo contido e tolerante, que é o ponto forte de civilidade de seu estilo - seu "Eu, ele e ela pensamos". Os estudos categoriais são eles mesmos apresentados a cada volta como conjuntos de argumentos abertos para o exame e discussão razoáveis. Alucidez dasanáliseséestonteanteeem certos momentos resulta em um trabalho de clarificação incomparável. Aprende-se enormemente algo que nunca se organizaria por si só, e certamente não por meio da leitura de Adorno, que demanda de seus leitores um entendimento virtualmente anamnésico de Marx, ao invés de fornecê-lo. Enquanto Moishe conhecia e podia explicar os Grundrisse nos mínimos detalhes, não há indicação, à exceção da citação ocasional de trechos conhecidos na Dialética negativa, de que Adorno tenha lido os Grundrisse inteiros. Por meio de um estudo cuidadoso, a interpretação que Moishe faz de Marx e da estrutura social se torna parte da própria mente e ilumina o mundo com nitidez, indo até o ponto de se tornar brilhante demais, e mesmo perturbador em sua proximidade. Por exemplo - e ainda que eu esteja agora agradecendo sinceramente a Bill Sewell por organizar esse colóquio -, se mesmo assim considerarmos a organização das conferências com seus incrementos de vinte minutos, que tento respeitar ao falar o mais rápido que consigo, é a lógica da obra sendo aqui homenageada que nos leva a reconhecer que o caráter estranhado dessa temporalidade com relação ao que cada um de nós tem a dizer dificilmente é de nossa própria fabricação, para não dizer a de Bill Sewell, e isso enquanto o reproduzimos. O que afixa o cronômetro da necessidade em posição elevada e a uma distância inescrutável de onde agimos - nas palavras de Moishe - é a manifestação da mediação total da sociedade pelo trabalho por meio da forma-mercadoria. Se a intenção

\footnotetext{
${ }^{12}$ Por exemplo: "O capital [...] é uma tentativa de construir uma argumentação que não tenha uma forma lógica independente do objeto investigado" (POSTONE, 2014, p. 166). Conforme ele explica algumas páginas depois, essa teoria não tem a pretensão de ser um ponto de vista exterior a seu objeto. Essa não é, contudo, a forma de apresentação que o próprio Postone queria desenvolver. Se a descrição de $O$ capital feita por ele é precisa, ela é então algo diferente de, como ele escreve, um argumento.
} 
dessa conferência é a de lembrar da obra de Moishe Postone, encontramo-nos, ao invés disso, demonstrando de forma declarada o princípio do tempo como necessidade para a qual o conjunto dessa obra se voltava a fim de discernir e de algum modo defletir. Nós nos organizamos em turnos para sermos tomados prisioneiros. Considerado funcionalmente - como Moishe demonstra -, nosso papel em nossos dias é o de exaurir nossas vidas produzindo aquilo que não deveria ser; fazemos o esforço de querer prová-lo sem perder a hora. Ao mesmo tempo, fica implícito nessa lógica que, a despeito de qualquer afirmação que possa ser feita sobre a totalidade da mediação da sociedade pelo trabalho, esse colóquio e a própria obra de Moishe provam que não é tudo o que fazemos que meramente exaure nossas vidas produzindo aquilo que não deveria ser.

É, então, ao seguir a lógica do trabalho de Moishe, sua análise de uma sociedade como sendo totalmente mediada pelo trabalho, que somos levados a considerar a preocupação última da filosofia como sendo a questão da totalidade: O que é tudo o que existe? Ou, para refazer essa questão, como faz Adorno, e do modo como ela nos tem sido devolvida desde a antiguidade, radicalmente reformulada pela experiência do século XX: Tudo o que existe é isso?³ Os comentários de Moishe com que comecei hoje refletem sobre essa questão em toda sua pungência quando ele escreve, "Nunca me senti tão desolado. Os EUA são um show de horrores e, como você sabe, as coisas parecem ir mal na Áustria”. É diante do desespero histórico - o terror de que isso realmente seja tudo o que existe, um mundo que agora entrou num ritmo de catástrofe que nunca será alcançado, quanto mais respondido - que as obras de Moishe Postone e Theodor Adorno são fundamentalmente aliadas. Mas, a despeito do quanto desejemos combinar o que há para aprender sobre a estrutura social a partir da obra de Moishe com a liberdade do objeto buscada pela filosofia de Adorno, o pensamento não é aditivo, ainda mais

\footnotetext{
${ }^{13}$ Ver Adorno (2001, p. 185); bem como suas palestras sobre a metafísica, em Adorno (1998, p. 224); e também na Dialética negativa, "Meditationen zur Metaphysik" [Meditação sobre metafísica]: "Uverkennbar wird reine metaphysische Erfahrung blasser und desultorischer im Verlauf des Säkularisierungsprozesses, und das weicht die Substantialität der älteren auf. Sie hält sich negativ in jenem Ist das denn alles?, das am ehesten im vergeblichen Warten sich aktualisiert." (ADORNO, 1986b, p. 368) ["Inegavelmente, a experiência metafísica pura torna-se mais pálida e mais fadada à desilusão no decurso do processo de secularização, e isso funde a substancialidade da experiência mais antiga." (2009, pp. 310-311)]. Ver ainda as palestras de Adorno (2018, notas 164 e 168) sobre a epistemologia em sua obra. O autor agradece à gentileza do editor Karel Markus por sua ajuda com essas referências.
} 
em se tratando de Postone e Adorno. Vindas de polos opostos da teoria crítica, suas reflexões não podem ser misturadas sincreticamente, como um conjunto de boas ideias juntadas de uma só vez. Conforme descobri, quando sentei uma vez com Moishe para entrevistá-lo sobre o assunto, ele sentia uma aversão visceral por Adorno, ainda que, naquele seu espírito de tolerância, nunca teria querido dizê-lo desse modo. Moishe havia lido muito pouco Adorno, e por isso levei a discussão em outra direção. Ainda assim, caso ele tivesse conseguido digerir os estudos deste último sobre o tempo musical, teria descoberto ali um compromisso com a questão última sobre a qual o conjunto de sua própria obra se volta, que é aquela do necessitarismo na temporalidade da produção capitalista. Pois a música é, afinal, uma reorganização do tempo que é bem-sucedida ou fracassa na conquista ou na ausência de um tempo dotado de sentido. Como conceber essa distinção de outro modo que não no sentido trivial da batucada, ou melhor ainda, no de sua crítica, pode de maneira rudimentar ser considerado como o que está em questão na musicologia de Adorno uma distinção que a obra de Moishe Postone assume e à qual aspira acima de tudo, mas que nunca desenvolve de fato, nem possuía os recursos para desenvolver. Entretanto, ainda que na obra de Adorno Moishe pudesse ter localizado as metamorfoses ovidianas na temporalidade concebível, caso tivesse feito isso, então não haveria um Tempo, trabalho e dominação social. Porém, ainda que reconheçamos o alcance da exclusividade mútua entre o ensaio como forma como crítica imanente e uma análise categorial sistemática da totalidade, essa antipatia não é para ser entendida como sendo obrigatoriamente improdutiva. Caso perseguida, ela pode até vir a ter implicações para a liberação de tudo aquilo que está contido como um híbrido na expressão "marxismo tradicional", desprendendo das aspas a experiência histórica e mesmo as palavras nela alojadas, sem botar em risco a reflexão sistemática do Marx maduro que Moishe acertadamente desejava discernir e elucidar. ${ }^{14}$

\footnotetext{
${ }^{14}$ Haveria, é claro, muito a se dizer quanto a isso, já que Adorno considerava sua própria obra como sendo imanente, transitiva e sistemática - além de necessariamente fragmentária. Adorno (2008) discute tais questões de forma detida em uma de suas séries de palestras mais provocantes: Philosophische Elemente einer Theorie der Gesellschaft (ed. Tobias ten Brink e Marc Phillip Nogueira). Ainda que eu não tenha reproduzido o raciocínio dele sobre esse ponto, este texto se alimenta de modo tão amplo do de Adorno que não seria possível anotar as muitas referências a ele, tanto explícitas quanto implícitas. Mesmo assim, o que há para se aprender a partir do estudo de Postone sobre o capitalismo, como já mencionado, não pode ser encontrado na obra de Adorno.
} 
Eu dificilmente diria que tenho a resposta para como isso pode ser realizado. Mas tenho uma ideia sobre a questão, que pode ser indicada recorrendo à responsabilidade que Moishe partilhou com a Esquerda por ter "falhado em imaginar ideias que teriam apelo para muitas pessoas de fora dos nossos círculos". Talvez, ao contrário de todas as aparências, a possibilidade esteja alojada precisamente aí, mesmo que exclusivamente pela negação determinada. Há, afinal, algo digno de nota no modo como o marxismo, ao longo do que são agora séculos, sempre e de novo parece estar se ajeitando na grande mesa da biblioteca, conforme se prepara para escrever a próxima popularização da economia política, se perguntando, perturbado, como comunicar o mecanismo da totalidade àquela população remota, alojada naqueles círculos sempre distantes. São as linhas de visão dessa mesa que merecem exame e talvez revisão. Pois percebam que, de onde a mesa está situada, o peuple inalcançável está exatamente à mesma distância do pensador e da totalidade incriminada. Os dois, o peuple e a totalidade, estão de fato situados tão precisamente no mesmo ponto triangulado, do outro lado da barreira, ou bloqueio, ou cerca, que os dois juntos estão, por assim dizer, pedindo para ser reconhecidos como dois aspectos de um único objeto, sua visada se alterando momentaneamente de acordo com a postura do pensador com relação a ele, indo do domínio triunfante sobre o todo ao reconhecimento doloroso de ter sido expulso da totalidade que afirma compreender. Ao buscar conhecer seu objeto sem deixar restos, a razão sistemática, com efeito, não tem escolha além de colocar implicitamente essa totalidade como absoluta. Como se diz às vezes, o amor pode até estar nos olhos de quem vê, mas, sem dúvida, a totalidade em si reside, de modo estrito e exclusivo, na mente de quem a vê. Se é assim, pode bem ser o caso de que o trabalho do pensador é que esteja constante e sistematicamente no processo de reconstruir o lado de cá da cerca, a partir do qual o objeto é sempre e de novo espiado, desaparecendo no horizonte. Mas isso só começa a indicar a complexidade. Pois o bloqueio é tão real e objetivo quanto o trabalho do pensador - como trabalho social -, como Moishe demonstrou de maneira tão brilhante, ao traçar a mediação da sociedade pela forma-mercadoria. Em outros termos, o bloqueio é o estabelecimento de um objeto do pensamento que é tanto real quanto ilusório. Pode-se morrer ao desafiá-lo. Moishe e Adorno concordam quanto a isso. E é ao compreender o ilusório e o coercitivo ao mesmo - e doloroso - tempo, em uma sociedade que se dilacera por meio da mesma dinâmica que a 
segura inteira, que o ensaio como forma e a apresentação sistemática da totalidade podem apresentar quais possibilidades existem ao longo desse limite difícil e desigual. Pois a crítica da dominação, ao querer por meio da capacidade subjetiva, e não de sua subtração, ser qualquer coisa que não outra perspectiva - não uma narrativa, não uma história -, é ao mesmo tempo encarada a cada ângulo pela questão de como a realidade pode ser levada a invadir a mente que a domina (HULLOT-KENTOR, 2008, pp. 23-28). A questão não pode ser concebida com muito orgulho, como se não passasse de uma acusação. Nem é a distância entre aquilo que é e aquilo que poderia ser algo da ordem do proverbial abismo escancarado, aguardando o prosseguimento das reflexões sobre o dilema entre teoria e prática antes de tentar de novo o salto mortale, talvez, dessa próxima vez, com uma cobertura melhor da imprensa. Ao contrário, o tal abismo é uma ilusão de ótica, é ele mesmo o pensamento aguardando que, "um dia, a lembrança do que foi perdido venha despertá-lo e o transforme em ensinamento" (ADORNO, 2006, p. 81). ${ }^{15}$ Essa pedagogia seria uma teoria social daquilo que é mais do que o que simplesmente existe, ao tornar necessária a experiência da insuficiência da mente - de novo, não de modo cético, não como narrativa, mas na determinação efetiva do real como sendo a própria experiência. Por mais que a expressão soe esquisita e errada, seria desejar direito.

Tradução de Tauan Tinti ${ }^{16}$

\section{REFERÊNCIAS}

ADORNO, Theodor W. Negative Dialectics. Trad. E. B. Ashton. Nova York: Continuum, 1981.

ADORNO, Theodor W. The Legacy of the German Refugee Intellectuals. Trad. Fredric Jameson. Salmagundi, Saratoga Springs, NY, ed. especial, 1969-1970.

ADORNO, Theodor W. The Essay as Form. Trad. R. Hullot-Kentor e F. Will. New German Critique, Durham, NC, n. 32, 1984a, pp. 151-171.

\footnotetext{
${ }^{15}$ N.T.: Referência da edição brasileira: Adorno (1992, p. 70).

${ }^{16}$ Doutor em Teoria e História Literária pelo IEL-Unicamp. Atualmente, é pesquisador de pós-doutorado (bolsa PNPD-Capes, processo n. 88887.363097/2019-oo) no Programa de Pós-graduação em Letras da Universidade Federal da Paraíba, sob supervisão do prof. Arturo Gouveia:<tauantinti@gmail.com>.
} 
ADORNO, Theodor W. The Idea of Natural History. Trad. R. Hullot-Kentor. Telos, Candor, NY, n. 6o, 1984b, pp. 111-124.

ADORNO, Theodor W. Kleine Häresie. Vol. 17. In: Gesammelte Schriften. Frankfurt am Main: Suhrkamp Verlag, 1986a.

ADORNO, Theodor W. Negative Dialektik. Vol. 6. In: Gesammelte Schriften. Frankfurt am Main: Suhrkamp Verlag, 1986b.

ADORNO, Theodor W. Prolog zum Fernsehen. Vol. 10.2. In: Gesammelte Schriften. Frankfurt am Main: Suhrkamp Verlag, 1986c.

ADORNO, Theodor W. Minima Moralia. Trad. Luiz Eduardo Bicca. São Paulo: Ática, 1992.

ADORNO, Theodor W. Metaphysik: Begriff und Probleme (ed. Rolf Tiedemann). Frankfurt: Suhrkamp, 1998.

ADORNO, Theodor W. Zur Lehre von der Geschichte und von der Freiheit (ed. Rolf Tiedemann). Frankfurt: Suhrkamp, 2001.

ADORNO, Theodor W. Minima moralia. Trad. E. F. N. Jephcott. Londres: Verso, 2006.

ADORNO, Theodor W. Philosophische Elemente einer Theorie der Gesellschaft (ed. Tobias ten Brink e Marc Phillip Nogueira). Frankfurt: Suhrkamp, 2008.

ADORNO, Theodor W. Dialética negativa. Trad. Marco A. Casanova. Rio de Janeiro: Zahar, 2009.

ADORNO, Theodor W. Against Epistemology. Trad. Willis Domingo. Londres: Polity, 2013.

ADORNO, Theodor W. Erkenntnistheorie (1957-1958) (ed. Karel Markus). Frankfurt: Suhrkamp, 2018.

HULLOT-KENTOR, Robert. A New Type of Human Being and Who We Really Are. Brooklyn Rail, Nova York, 10 nov. 2008, pp. 23-28.

LEBRUN, Gerard. La Patience du concept: essai sur le discours hégélien. Paris: Gallimard, 1972.

POSTONE, Moishe. Time, Labor, and Social Domination: A Reinterpretation of Marx's Critical Theory. Cambridge: Cambridge University Press, 1993.

POSTONE, Moishe. Tempo, trabalho e dominação social: Uma reinterpretação da teoria crítica de Marx. Trad. Amilton Reis e Paulo Cézar Castanheira. São Paulo: Boitempo, 2014.

POSTONE, Moishe. [Correspondência por e-mail]. Destinatário: Robert Hullot-Kentor. Viena, 2017. 
POSTONE, Moishe; BRENNAN, Timothy. Labor and the Logic of Abstraction: An Interview. South Atlantic Quarterly, Durham, NC, v. 108, n. 2, 2009, p. 325.

Recebido: 2/2/2021

Aceito: $1 / 4 / 2021$

Publicado: 21/6/2021 